\title{
RELAÇÕES DE PARENTESCO E DESEMPENHO ELEITORAL NAS ELEIÇÕES PROPORCIONAIS DE 2008 EM CURITIBA ${ }^{1}$
}

\author{
José Lazaro Ferreira Barros Junior ${ }^{2}$
}

- Enviado em 22/08/2015

- Aprovado em 10/09/2015

\begin{abstract}
RESUMO
O artigo retoma os principais aspectos da dissertação defendida no programa de Mestrado em Sociologia da UFPR, quando estive vinculado ao Núcleo de Estudos Paranaenses (NEP), de forma a enfatizar uma modelagem de pesquisa sobre relações de parentesco e desempenho eleitoral. $\mathrm{Na}$ ocasião, buscou-se examinar os componentes da trama de relacionamentos embutidos na conquista do voto, adotando como ponto de partida a pesquisa de Miguel (2003b) sobre a estruturação da carreira política no Brasil - onde a noção de capital social aparece como hipótese de entendimento para o sucesso de candidatos "novatos". Das estatísticas de desempenho eleitoral e da pesquisa prosopográfica sobre os vereadores eleitos em 2008 na cidade de Curitiba - capital do Paraná, então com aproximadamente 1,7 milhão de habitantes - foram selecionados 6 dos 38, que passaram por uma etapa qualitativa cujo objetivo era mostrar o acesso diferenciado destes aos recursos enraizados nas redes sociais, associações civis e sistemas de confiança compartilhada. Assim, o capital social é dissecado no nível interpessoal, revelando estratégias eleitorais: a mediação de recursos e informação, a demonstração de pertencimento a famílias tradicionais, e a inserção em comunidades que compartilham características demográficas ou interesses em comum.
\end{abstract}

Palavras-chave: Comportamento político. Eleições. Capital social. Relações de parentesco.

\section{INTRODUÇÃO}

Para a realização da dissertação "Desempenho eleitoral nas eleições proporcionais de 2008 em Curitiba", defendida cinco anos atrás, em 2009, buscou-se aflorar o sistema de relações pessoais e institucionais dos políticos analisados, no qual acreditava-se que parte do resultado eleitoral estaria embutido. Prosopografia e pesquisa qualitativa foram combinadas para tratar empiricamente uma hipótese levantada pelo cientista político Luís Felipe Miguel, ${ }^{3}$ que propunha ser a conversão de

\footnotetext{
1 Dissertação defendida em 23 de março de 2011. Versão completa disponível na Biblioteca Digital da UFPR http://dspace.c3sl.ufpr.br:8080/dspace/handle/1884/32232.

${ }^{2}$ Graduado em Comunicação Social - Jornalismo pela UFPR. Mestre em Sociologia pela mesma instituição. Um dos idealizadores do projeto Livre.jor, que produz notícias estritamente a partir de dados oficiais. Jornalista do quadro próprio da Câmara Municipal de Curitiba. Endereço eletrônico: zelazaro@gmail.com
}

3 Miguel é professor titular da Universidade de Brasília (UnB), vinculado ao Instituto de Ciência Política. Trabalha nas áreas de teoria da democracia, representação política e gênero. Coordena o Grupo de 
outros capitais em capital político a explicação para a eleição de deputados federais "novatos" na política - quer dizer, sem experiência anterior com vitória eleitoral (Miguel 2003b). Essa circunstância inspirou a adoção do modelo como abordagem para câmaras de vereadores - em que o número de "novatos", em tese, é maior.

Teoricamente informada por noções utilizadas pelo sociólogo Pierre Bourdieu, de quem Miguel adotou as ideias de "campo político", "capital político" e "capital social", a pesquisa que resultou na dissertação tratou de agrupar a tipologia de capital social dispersa na literatura nacional e internacional. O resultado foram sete situações diferentes, estudadas em vários ramos das ciências sociais, com alta aderência à ideia de conversão de capital social em capital político - a saber: capital social de ligação, de ponte, de conexão, imperativo moral, solidariedade comprometida, relações de parentesco e comunicadores sociais. Todas hipóteses viáveis para explicar como o desempenho eleitoral de candidatos a cargos de representação política varia conforme estes se relacionam com redes sociais, associações civis, e sistemas de confiança compartilhada.

O objetivo deste artigo é recuperar esse raciocínio, de forma que ele seja tanto um guia para leitura da dissertação, quanto uma agenda de pesquisa para novas e mais aprofundadas investigações sobre o tema. Contudo, aqui será dada ênfase em um dos sete tipos de conversão, que é influência das relações de parentesco no desempenho eleitoral dos candidatos. Depois de apresentado um rápido panorama dos estudos eleitorais no Brasil, do raciocínio de Miguel sobre a estruturação da carreira política no país, e da teoria que embasou a dissertação, uma seção específica do artigo recuperará integralmente os aspectos relacionados às relações de parentesco. Os estudos de caso brevemente reproduzidos aqui, na parte final do texto, também estarão ligados diretamente ao tema.

Dentro do Núcleo de Estudos Paranaenses, da Universidade Federal do Paraná, existem trabalhos anteriores sobre os políticos que compuseram a Câmara Municipal de Curitiba. Uma destas peças, por exemplo, reuniu farto material sobre os últimos 50 anos de eleições municipais na cidade. É a dissertação defendida em 2008 por Mauro Pioli Rehbein, na qual ele reúne dados sobre as eleições realizadas de 1947 a 2004, descrevendo nominalmente a sucessão dos candidatos e as mudanças nos grupamentos políticos, pleito após pleito.

Em certa medida, as pesquisas que realizei na especialização e mestrado, seguem o caminho apontado por Rehbein - de reflexão sobre o poder local como objeto de estudo. Dada a vinculação de ambos com o NEP, é tema comum nas duas dissertações como o pertencimento a famílias 
tradicionais é em parte responsável por moldar o poder político. ${ }^{4} \mathrm{O}$ tema historicamente permeia a literatura dos estudos eleitorais, apesar da sua formulação clara como objeto de estudo ser bastante recente.

Desde os anos 1940, pensadores já analisam a dinâmica das eleições realizadas no Brasil. No início, tratou-se das condições que reduziam a autonomia de decisão do eleitorado, como as práticas coronelistas exercidas pelas aristocracias estaduais e o sistema clientelista de troca. A partir de 1950 e 1960, dados da Justiça Eleitoral começam a fundamentar estudos mais abrangentes sobre as características do eleitorado, possíveis correlações entre informações demográficas e a escolha dos candidatos, a composição dos partidos políticos e o perfil dos vencedores das disputas eleitorais. Na década de 1970, a pesquisa acadêmica incorpora a utilização de novas ferramentas investigativas e busca o contato direto com o eleitor, ainda produzindo resultados vagos. Há um lapso na década seguinte, que será superado nos anos 1990. Então, é recentemente, e de maneira distinta, que trabalhos importantes surgirão nos campos da ciência política, sociologia eleitoral e antropologia política. Aos poucos, também serão incorporados aspectos da comunicação social e marketing às agendas de pesquisa (SILVEIRA, 2002).

Esta trajetória está sucintamente descrita no trabalho em que o pesquisador Flávio Silveira (2002) busca diferenciar tecnicamente pesquisas, enquetes e estudos eleitorais. Ele faz um apanhado dos trabalhos acadêmicos que teriam marcado diferentes momentos do pensamento político brasileiro nesta área a partir de 1930. Ao todo, o pesquisador lista 76 títulos e 48 autores, distribuindo-os nestas cinco diferentes épocas. Quem desejar se aprofundar no assunto tem ali um roteiro de leitura, cuja compreensão melhora se confrontado com o relato da luta pela hegemonia no campo da ciência política nacional (KEINERT; SILVA, 2010). ${ }^{5}$

\section{CARREIRA ELEITORAL E CAPITAL POLÍTICO}

Um artigo científico publicado por Miguel (2003b) sugere a existência de regularidades na trajetória política de candidatos eleitos para o Congresso Nacional da $48^{\text {a }}$ a $51^{\text {a }}$ legislaturas (1986, 1990, 1994 e 1998 respectivamente). Os políticos, antes dos pleitos em nível federal, teriam

\footnotetext{
${ }^{4}$ Especialmente os trabalhos do pesquisador Ricardo Costa de Oliveira, orientador da dissertação e coordenador do NEP, têm obtido sucesso em incentivar investigações sobre a influência dos laços familiares na composição de alianças entre elites políticas, cujos desdobramentos chegam à ocupação de postos públicos e direcionamento de políticas públicas (OLIVEIRA 2001, 2004, 2007 e 2012).

${ }^{5}$ A adequada contextualização do problema de pesquisa pediria também o conhecimento de textos clássicos sobre as instituições brasileiras (por exemplo FAORO, 1958; MAINWARING, 1993; SANTOS, 1997; SANTOS, 1986; ABRANCHES, 1988; ABRUCIO, 1998; CAMARGO, 2001).
} 
vivenciado experiências semelhantes, nas quais ocuparam cargos em âmbito municipal, como vereadores e/ou prefeitos de cidades pequenas, ou desempenhando papéis nos poderes Legislativo e Executivo estaduais. Esta é a primeira constatação do pesquisador.

A segunda é a diferença no prestígio atribuído a cada cargo, de forma que o cargo de vereador é a base do diagrama de carreira eleitoral e a presidência da República o ponto mais alto — conforme a relação demonstrada na Figura $1 .^{6}$

FIGURA 01

Estrutura da carreira eleitoral no Brasil

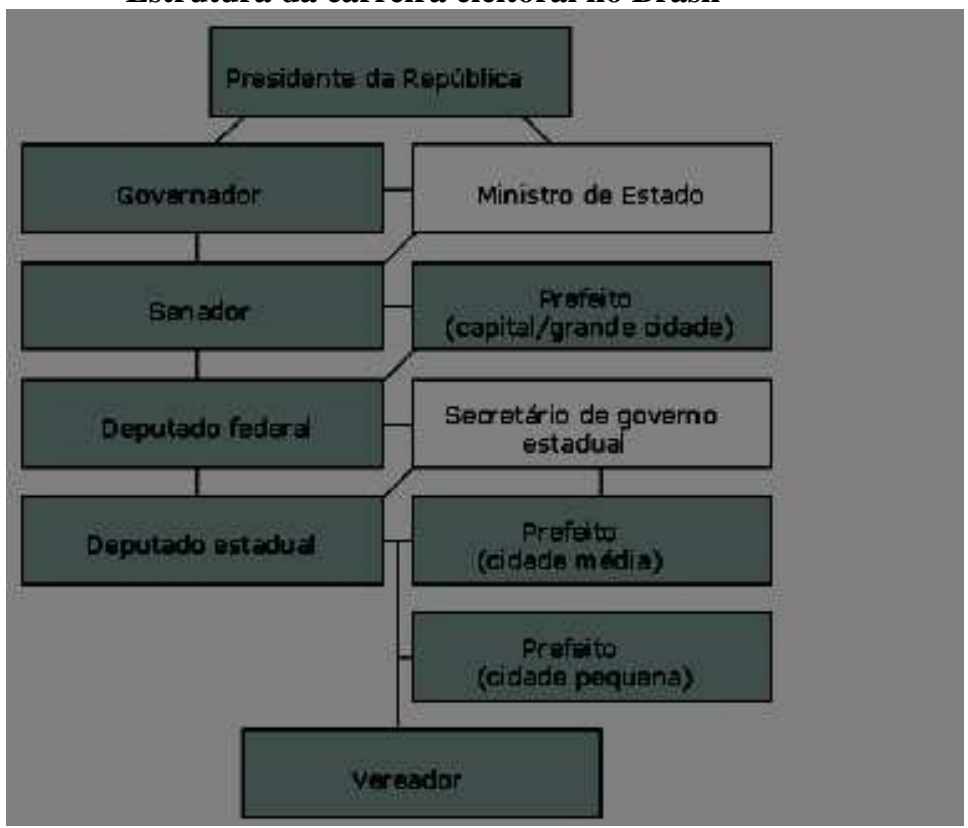

FONTE: MIGUEL (2003b, p. 117)

Para informar teoricamente os dados empíricos resumidos no diagrama, Miguel busca em Bourdieu o léxico que considera apropriado. Ele trata os votos recebidos pelos candidatos como capital político e a carreira eleitoral como uma das manifestações do campo político.

Capital político seria, resumidamente, um enunciado para descrever a circunstância na qual uma pessoa reconhece na outra as condições que julga necessárias para que este lhe represente. Ou seja, detém capital político aquele um que é capaz de inspirar nos outros o sentimento de que ele próprio é competente para a tarefa em questão: ser presidente da República, síndico do prédio, dirigente partidário.

Miguel distingue ainda, dentro do léxico de Bourdieu, o "capital político delegado" do

\footnotetext{
6 "Os políticos atribuem pesos diferenciados aos cargos que podem vir a ocupar, optando por aqueles que julgam mais importantes ou prestigiosos. Uma vez que tais julgamentos quase sempre coincidem, é possível dizer que o campo político estrutura-se como uma carreira hierarquizada (...) Como regra, postula-se que quem está na base da pirâmide deseja ascender, mas como as vagas em cada etapa são menos abundantes, gera-se uma competição permanente" (MIGUEL, 20003b, p. 115).
} 
"capital político convertido". A pessoa que detém recursos do primeiro tipo já ocupou cargos de gestão pública ou direção partidária antes do pleito a que está se submetendo - e espera que suas ações anteriores, no mesmo campo de atuação para o cargo que atualmente concorre, bastem para credenciá-lo na nova empreitada.

O "capital político convertido", no contraponto da visão anterior, seria percebido quando o vencedor da disputa recebe votos não pela vivência anterior na área da concorrência, mas por ter se sobressaído em algum outro aspecto da vida que ele comunga com o eleitor. Neste caso, o eleitor é quem converteria intimamente essa experiência em um voto de confiança, cujo resultado é igualmente capital político.

Este raciocínio advoga que vence as eleições o candidato cujas habilidades fazem com que ele seja reconhecido pela sociedade como capaz de representar os interesses dela emanados — ou seja, aquele que mobiliza mais capital político. As duas palavras fundamentais nesta sentença são "habilidade" e "interesses", cujos significados propositadamente abertos foram escolhidos para simbolizar diferentes aspectos do jogo político - do puro debate ideológico a formas contemporâneas de clientelismo.

Miguel (2003b), por sua vez, constatou que, para participar da disputa de capital político dentro do campo político, a maioria segue a via ortodoxa. Ela consiste em filiar-se a um partido político, participar das questões de interesse da legenda e, ao mover-se dentro da estrutura por ela disponibilizada de ganho de popularidade (eleitores e financiadores de campanha), tornar-se apto a disputar e vencer sucessivas eleições. ${ }^{7}$

Contudo, o pesquisador percebeu a ocorrência de uma minoria que estreava na política já ocupando cargos mais prestigiosos, deixando a etapa local para trás e seguindo direto para o Congresso Nacional. Miguel os chamou de deputados novatos.

Para identificar a origem dos deputados novatos, ele estudou separadamente a evolução da bancada do Partido dos Trabalhadores (PT) nas legislaturas anteriormente citadas, por considerá-lo um partido de pouca mobilidade de correligionários e grande votação de legenda — o que demonstraria uma maior institucionalização da estrutura partidária: "Em 1986, a esmagadora maioria dos deputados petistas novatos (que, por sua vez, eram a esmagadora maioria da bancada petista) não tinha ocupado cargos políticos anteriormente. O padrão era a passagem direta da liderança sindical para a Câmara dos Deputados" (MIGUEL, 2003b, p. 124).

Nestes casos, a origem do capital político necessário para a vitória não foi delegado pela

\footnotetext{
7 “Ao contrário do capital pessoal que desaparece com a pessoa do seu portador (embora possa originar querelas de herança), o capital delegado de autoridade política é, como o do sacerdote, do professor e do funcionário, produto da transferência limitada e provisória (apesar de renovável) de um capital detido e controlado pela instituição e só por ela" (BOURDIEU, 2000, p. 191).
} 
instituição partidária diretamente. O modelo teórico indica que a acumulação se deu na conversão de outras habilidades em capital político, como o sucesso empresarial, o prestígio intelectual, a popularidade advinda de atividades artísticas, o pertencimento à família política tradicional ou a participação em iniciativas de associativismo civil. ${ }^{8}$

Ao trazer a discussão do nível federal para o municipal, um vereador é semelhante a um "deputado novato". Ambos cruzaram portas de entrada para o campo político, logo as categorias de análise de um caem bem no outro. Entendo que a análise da conversão de outras habilidades em capital político, feita na base do diagrama eleitoral, não significa entender como a minoria do Congresso Nacional chegou ao poder, mas compreender as condições para o nascimento de um político de carreira.

Para Bourdieu, cada grupamento comunga de características que determinam não somente o ambiente em que o indivíduo atua, mas também a atuação ela mesma - a "teoria geral dos campos" (BOURDIEU, 2000, p. 27). A questão é que em um "espaço social estruturado, um campo de forças, há dominantes e dominados". Ele chama a atenção para constantes relações de desigualdade dentro deste espaço, que fazem da convivência entre esses concorrentes um campo de lutas (BOURDIEU, 1996, p. 57).

O campo político, entendido ao mesmo tempo como campo de forças e como campo de lutas que têm em vista transformar a relação de forças que confere a este campo a sua estrutura em dado momento, não é um império: os efeitos das necessidades externas fazemse sentir nele por intermédio sobretudo da relação que os mandantes, em consequiência da sua distância diferencial em relação aos instrumentos de produção política, mantêm com os seus mandatários e da relação que estes últimos, em conseqüência das suas atitudes, mantêm com as suas organizações (BOURDIEU, 2000, p. 163-164).

Ao constatar a discrepância numérica entre os políticos e aqueles que eles representam, o povo, Bourdieu (2000, p. 166) afirmou que "o mercado da política é, sem dúvida, um dos menos livres que existem", pois a produção de bens nele está restrita ao próprio corpo de profissionais que dele se serve. Quanto maior a competição no campo político, mais alertas ficam os sujeitos ao

\footnotetext{
${ }^{8}$ O "capital político convertido" é uma síntese elaborada por Miguel (2003b) a partir de dois tipos de capital "pessoal" presentes na obra de Bourdieu (2000, p. 190-191), o notável e o heroico: "O capital pessoal de "notoriedade" e de "popularidade" - firmado no fato de ser conhecido e reconhecido na sua pessoa (de ter um "nome", uma "reputação", etc.) e também no fato de possuir um certo número de qualificações específicas que são a condição da aquisição e da conservação de uma "boa reputação" - é frequentemente produto da reconversão de um capital de notoriedade acumulado em outros domínios e, em particular, em profissões que, como as profissões liberais, permitem tempo livre e supõem um certo capital cultural ou, como no caso dos advogados, um domínio profissional da eloquência. Enquanto este capital pessoal de notável é produto de uma acumulação lenta e contínua, a qual leva em geral toda uma vida, o capital pessoal a que se pode chamar de heroico ou profético e no qual pensa Max Weber quando fala de "carisma" é produto de um uma ação inaugural, realizada em situação de crise, no vazio e no silêncio deixados pelas instituições e pelos aparelhos: ação profética de doação de sentido, que se fundamenta e se legitima ela própria, retrospectivamente, pela confirmação conferida pelo seu próprio sucesso à linguagem de crise e à acumulação inicial de força de mobilização que ele realizou".
} 
acesso de novatos e à presença de oportunistas.

Refletindo sobre os "oportunistas", Miguel (2003b) formula três fontes principais de outros capitais usualmente convertidos em vantagem política: o capital cultural (treinamento cognitivo para a ação política), capital econômico (que favorece o seu detentor com o ócio necessário à prática política, permitindo-lhe não possuir outras atribuições para a sobrevivência e satisfação pessoais) e capital social (redes sociais, associações civis e sistemas de confiança compartilhada).

\section{CAPITAL SOCIAL}

Enquanto as noções de capital econômico e cultural são facilmente compreensíveis como equivalentes de dinheiro e títulos de distinção, a ideia de capital social tem suscitado inúmeros debates no meio acadêmico.

O pioneirismo de Bourdieu nesta área de pesquisa é defendida por Portes (2000), sociólogo que estuda a imigração nos Estados Unidos. Ele teria identificado em Bourdieu a primeira tentativa de desnaturalização das redes sociais, quando o cientista social francês diz que as relações interpessoais possuem um caráter instrumental. Para Bourdieu, os agentes participariam de grupos, da construção de quaisquer tipos de sociabilidades, para a obtenção de benefícios.

O capital social é o conjunto de recursos atuais ou potenciais que estão ligados à posse de uma rede durável de relações mais ou menos institucionalizadas de interconhecimento e de inter-reconhecimento ou, em outros termos, à vinculação a um grupo, como conjunto de agentes que não somente são dotados de propriedades comuns (passíveis de serem percebidas pelo observador, pelos outros ou por eles mesmos), mas também são unidos por ligações permanentes e úteis. Essas ligações são irredutíveis às relações objetivas de proximidade física (geográfico) ou no espaço econômico e social porque são fundadas em trocas inseparavelmente materiais e simbólicas cuja instauração e perpetuação supõem o reconhecimento dessa proximidade (...) Os lucros que o pertencimento a um grupo proporciona estão na base da solidariedade que os torna possível (BOURDIEU, 2007, p.67).

Esta definição de capital social foi divulgada por Bourdieu em 1980, em um artigo publicado na revista Actes de la recherche en sciences sociales. Intitulado "Capital social - notas provisórias", ele é editado em português no ano de 1998, integrando uma coleção sobre educação. O mesmo aconteceu nos países de língua inglesa, onde a conceituação teria passado despercebida, conforme aponta Portes (2000, p. 135) ${ }^{9}$.

\footnotetext{
9 "Por se encontrar em francês, o artigo não colheu uma atenção generalizada no mundo de língua inglesa; nem, de resto, a obteve a primeira tradução inglesa, escondida nas páginas de um compêndio sobre sociologia da educação (BOURDIEU, 1985). Esta falta de visibilidade é lamentável, na medida em que a análise de Bourdieu pode ser considerada como a que apresenta maior refinamento teórico entre aquelas que introduziram o termo no discurso
} 
O fato auxilia o entendimento de parte dos motivos que fizeram mais famosa, na atualidade, a definição dada por outro pesquisador: o cientista político Robert Putnam. Preferindo estudar grandes áreas a se concentrar em pequenas comunidades ou relacionamentos interpessoais, Putnam é o responsável pela popularização mundial do termo, como demonstrado por Fukuyama (2002, p.158): "[Putnam] estimulou um intenso debate sobre o papel do capital social e da sociedade civil na Itália e nos Estados Unidos”, na medida em que relacionava a confiança interpessoal com a participação em associações cívicas, o envolvimento em questões públicas, o comportamento de obediência à lei e a confiança nas instituições como catalisadores da solução de conflitos. ${ }^{10}$

Para Putnam, capital social são características da vida social (redes, normas e confiança) que capacitam os seus participantes a agirem em conjunto de forma mais eficaz para atingirem os objetivos anteriormente partilhados (CASTRO, 2006, p. 09), como no exemplo das associações de crédito rotativo (PUTNAM, 1994, p. 177). Outro autor cuja definição de capital social dialoga com a de Bourdieu é a do sociólogo James Coleman. Ele será o responsável por "introduzir e conferir visibilidade ao conceito na sociologia norte-americana, sublinhando a sua importância na geração de capital humano e identificando alguns dos mecanismos através dos quais é gerado" (PORTES, 2000, p.137). Coleman entendia o capital social como um recurso coletivo, cuja existência tornava possível a execução de atividades impossíveis de serem realizadas individualmente.

Social capital it's defined by its function. It's not a single entity but a variety of different entities, with two elements in common: they all consist of some aspect of social structures, and they facilitate certain actions of actors - whether persons or corporate actors - within the structure. (...) Unlike other forms of capital, social capital inheres in the structure of relations between actors and among actors. It is not lodged either in the actors themselves or in physical implements of production (COLEMAN, 1988, p. 98). ${ }^{11}$

Bourdieu concordará quanto à intangibilidade do capital social (PORTES, 2000, p. 138), mas irá afirmar que ele e todas as outras formas de capital poderão ser reduzidas a capital econômico ou, ao menos, a títulos simbólicos de distinção. Outra característica que também despertará posicionamentos semelhantes de ambos é a questão da durabilidade.

Para Coleman, o capital social não é consumido pelo uso. Ao contrário, é na ativação das

sociológico contemporâneo" (PORTES, 2000, p.135).

${ }^{10}$ Sobre as dúvidas a respeito de se confiar nas medidas de confiança, e as opções metodológicas, ver CASTRO (2006), LUNDASEN (2002), STONE (2001) e LIN (1999).

11 Tradução livre: "O capital social é definido pela sua função. Não é uma entidade única, mas uma variedade de diferentes entidades, com dois elementos em comum: todas elas consistem de alguns aspectos das estruturas sociais e facilitam certas ações dos atores - sejam pessoas ou atores corporativos - dentro da estrutura. (...) Ao contrário de outras formas de capital, o capital social reside na estrutura das relações dos atores e entre os próprios atores. Ele não está alojado na pessoa dos atores tomados isoladamente, nem nos aspectos físicos da sua produção" (COLEMAN, 1988, p. 98). 
relações sociais que o capital social fica mais perene (AQUINO, 2000, p. 25). Bourdieu (2007, p.68), considerando as pessoas animadas por um senso prático, afirma que "a existência de uma rede de relações [é] o produto do trabalho de instauração e de manutenção que é necessário para produzir e reproduzir relações duráveis e úteis, aptas a proporcionar lucros materiais ou simbólicos".

Coleman também observou que as diferenças de natureza entre as redes sociais afetavam a qualidade da confiança individual no interior das redes - levando a conclusão que o ambiente é uma importante variável para o entendimento das tomadas de decisão (BROWN, 1999, p. 02). Ele e Bourdieu nunca debateram as diferenças e semelhanças dos seus trabalhos, mas é Coleman o primeiro a citar o sociólogo francês em língua inglesa. ${ }^{12}$

O debate simbólico entre Putnam, Coleman e Bourdieu revela uma questão latente na pesquisa de Miguel: ainda que solidariamente, ela divide pontos com a tradição culturalista. Com isto se quer dizer que, apesar da investigação sobre a conformação da carreira eleitoral no Brasil não ter sido realizada integralmente dentro das especificidades do campo - ainda às voltas com as ideias de cultura cívica, desempenho institucional e promoção da democracia —, parte dela deve a esta matriz sociológica os instrumentos de pesquisa. É o caso da noção de capital social.

\section{TIPOLOGIA E ELEIÇÃO DE 2008}

Para Bourdieu, a noção de capital social pode ser muito bem aproveitada na sociologia para traduzir acontecimentos que surgem do contato interpessoal. Afinal de contas, dirá o cientista social francês, eles podem ser percebidos pela análise das condutas individuais (como faz a estatística), mas só encontram explicação no coletivo. É nesse sentido que Nan Lin, cientista social da Universidade de Duke, dirá que a medição do capital social "deve levar em conta (i) quão extensa é a rede em que a pessoa se insere (ii) qual o nível mais elevado nele alcançado e (iii) como se distribuem as relações nesse intervalo (DEGENNE, 2004, p. 304)”.

Durante a tipificação dos candidatos eleitos em 2008, além dos apontamentos de Lin (2001) foi considerada também a classificação das redes sociais feita em 1973 por Granovetter, dividindo os laços sociais em dois tipos: fortes e fracos. Os laços fortes são aqueles em que os indivíduos despendem mais tempo, intensidade emocional e trocas, como as relações de amizade e parentesco.

\footnotetext{
12 A referência encontra-se no livro "Foundations of social theory", de 1990. Na passagem, Coleman atribui ao economista Glen Loury a origem do termo e cita Bourdieu como um dos autores que também utilizou o conceito capital social (COLEMAN, 1990, p. 300).
} 
Já os fracos são aqueles em que o investimento por parte das pessoas é menor ou nulo, como os contatos esporádicos com colegas de trabalho, aos quais só se deseja "bom dia" (MARTELETO e SILVA, 2004, p. 43).

Considerando relações interpessoais formadas por laços sociais fortes e fracos, as redes sociais podem ser classificadas em três tipos distintos (de ligação, de ponte e de conexão). Duas classificações adicionais, "imperativo moral" e "solidariedade comprometida" foram elaborados por Portes (2000). E, da contribuição brasileira, incluímos o papel dos comunicadores sociais e das relações de parentesco nos tópicos abordados pela dissertação.

$\mathrm{Na}$ ocasião, o exercício foi buscar o capital social preponderante na trajetória política de cada vereador eleito - sem querer, com isso, reduzir a atuação dele a este aspecto. Imaginava-se que isolando aspectos seria mais fácil compreender a dinâmica social embutida na transformação de relações de confiança em votos. A seguir, apresentaremos (i) os dados gerais da eleição proporcional de 2008 em Curitiba, (ii) apontamentos sobre o impacto das relações de parentesco no desempenho bem-sucedido de 5 dos 38 eleitos, e (iii) a classificação dos demais - apenas para registro.

Nas eleições de 2008, a população da cidade era de 1.828 .092 pessoas, tendo aumentado $5,8 \%$ desde a última disputa, quatro anos antes. Estavam aptos a votar 1.254.776 eleitores, marca que representa um novo aumento de $6 \%$ no eleitorado da capital. A representatividade manteve-se estável em 68\%. No dia das eleições, 1.068.613 moradores da cidade compareceram para votar — o que significa dizer $85 \%$ dos eleitores habilitados e $58 \%$ dos residentes no município.

Considerado apenas o número de votos válidos, que chegou a 965.083, o porcentual de moradores da capital efetivamente envolvidos no processo eleitoral cai para 53\%. A situação mostra que a competição entre os candidatos é mais acirrada do que se imaginaria em um primeiro momento, com menos possibilidade de sucesso e taticamente mais exigente. Na outra ponta desta relação, mostra que o eleitor que comparece às urnas e valida o voto está mais empoderado do que poderia supor à primeira vista. Os atores que percebem essa situação exigem níveis mais altos de cooperação.

A eleição de 2008 teve um acréscimo de $42 \%$ no número de candidatos, com 794 políticos disputando as 38 vagas disponíveis no legislativo municipal. A relação candidato/vaga subiu junto, com cada grupo de 21 políticos disputando um gabinete na Câmara Municipal. Onze partidos políticos obtiveram assento no legislativo municipal. A taxa de reeleição caiu pelo segundo ano consecutivo, ficando em 55\% com a recondução de 21 vereadores: Pastor Valdemir (PRB), Serginho do Posto (PSDB), Felipe Braga Côrtes (PSDB), João Cláudio Derosso (PSDB), Jairo Marcelino (PDT), Beto Moraes (PSDB), Tito Zeglin (PDT), Aldemir Manfron (PP), Sabino Picolo 
(DEM), Dona Lourdes (PSB), Paulo Frote (PSDB), Celso Torquato (PSDB), Zé Maria (PPS), Roberto Hinça (PDT), Jair Cezar (PSDB), Mario Celso (PSB), Aladim (PV), Julieta Reis (DEM), Pedro Paulo (PT) e Professora Josete (PT).

Lendo a estatística ao contrário, pode-se afirmar que a Câmara Municipal de Curitiba foi renovada quase pela metade em 2008. Dos $45 \%$ que conquistaram um mandato na casa, sete já haviam disputado outra eleição para o mesmo cargo desde 1992. São eles: Professor Galdino (PSDB), Francisco Garcez (PSDB), João do Suco (PSDB), Odilon Volkmann (PSDB), Juliano Borghetti (PP), Noemia Rocha (PMDB) e Dirceu Moreira (PSL). Outros dez foram eleitos sem terem concorrido ao cargo de vereador nos últimos 16 anos. Roberto Aciolli (PV), Mara Lima (PSDB), Denilson Pires (DEM), Emerson Prado (PSDB), Omar Sabbag Filho (PSDB), Renata Bueno (PPS), Algaci Tulio (PMDB), Julião Sobota (PSC), Jonny Stica (PT) e Caíque Ferrante (PRP) foram os parlamentares "novatos" desta eleição ${ }^{13}$.

O sistema eleitoral brasileiro não considera somente os votos nominais para a elaboração da lista de políticos vencedores das eleições. Ele computa também a votação de legenda para a obtenção do quociente eleitoral, o que faz com que nem sempre os mais votados sejam os candidatos eleitos. Na eleição de 2008, o vereador mais bem-sucedido foi Roberto Aciolli (PV), com 17.377 votos, mas Dirceu Moreira (PSL), que obteve a última vaga com apenas 2.593 votos, ficou no $80^{\circ}$ lugar se considerada apenas a votação nominal.

Para existir capital social Bourdieu entende que é preciso um trabalho de instauração e de manutenção, condição para que as relações interpessoais aconteçam e perdurem — podendo, em algum momento, gerar vantagens materiais ou simbólicas para os participantes dessa sociabilidade.

É por isso que a reprodução do capital social é tributária, por um lado, de todas as instituições que visam a favorecer as trocas legítimas e a excluir as trocas ilegítimas, produzindo ocasiões (rallys, cruzeiros, caçadas, saraus, recepções, etc.), lugares (bairros chiques, escolas seletas, clubes, etc.) ou práticas (esportes chiques, jogos de sociedade, cerimônias culturais, etc.) que reúnam, de maneira aparentemente fortuita, indivíduos tão homogêneos quanto possível, sob todos os aspectos pertinentes do ponto de vista da existência e da persistência do grupo (BOURDIEU, 2007, p. 68).

O senso prático das pessoas as compeliria a dispor constantemente de tempo e atitudes para manter ativo o capital social já criado. Isto pode significar a participação nas ocasiões, lugares ou atividades do grupo de interesse, ou a substituição da presença física por capital econômico. Contudo, Bourdieu adverte que, quanto mais prestigiadas são as relações interpessoais em questão, mais importante é o capital social.

\footnotetext{
${ }^{13}$ Durante cinco legislaturas, estiveram disponíveis 179 cadeiras de vereador na Câmara Municipal de Curitiba. Ao longo desse período, 88 políticos se revezaram na ocupação dessas vagas, sendo que 45 trocaram de legenda ao menos uma vez durante todo o período. Dos 88 , apenas 11 são mulheres.
} 
Seria o caso dos "herdeiros de capital social", presente nas tradicionais famílias políticas.

Todo o complexo de relações sociais duráveis dos antepassados acaba reduzido em um símbolo de distinção culturalmente apropriado: o sobrenome.

Parte significativa dos políticos eleitos durante as últimas cinco legislaturas da Câmara Municipal de Curitiba ${ }^{14}$ possui parentesco com personagens da recente história política paranaense, dos governos municipal e estadual, dos quais herdaram capital político associado à atuação institucional de seus antecessores. Na eleição de 2008, foram eleitos cinco candidatos com esse perfil.

O rendimento desse trabalho de acumulação e manutenção do capital social é tanto maior quanto mais importante for esse capital, sendo que o limite é representado pelos detentores de um capital social herdado, simbolizado por um sobrenome importante, que não têm que "relacionar-se" com todos os seus "conhecidos", sendo procurados por ser seu capital social, e tendo valor porque "conhecidos" (cf. "eu o conheci bem"), estão em condições de transformar todas as relações circunstanciais em ligações duráveis (BOURDIEU, 2007, p. $67)$.

Em 2008, a reeleição do vereador João Claudio Derosso (PSDB) foi alcançada com 11.189 votos nominais. Foi a sexta recondução do político ao cargo de vereador da cidade. Em 1992, foi eleito pelo PDT com 6.462 votos. Reeleito em 1996, com 7.416. Reeleito em 2002, pelo PFL, com 12.852 votos. Reeleito em 2004, pelo PSDB, com 14.991. Durante estes 24 anos, Derosso foi presidente da Câmara Municipal de Curitiba em doze. Como chefe do poder Legislativo, ele assumiu a Prefeitura de Curitiba por oito vezes, em momentos de ausência do prefeito e viceprefeito.

\begin{abstract}
Na minha primeira eleição [anterior ao período da amostragem], a maioria dos meus votos veio do Xaxim, onde continuam até hoje. $\mathrm{E}$ poucos votos pingados, de amigos da faculdade, espalhados pela cidade (...) Com o tempo, o trabalho do vereador não se restringe aos bairros de origem. Você vai tentar resolver os problemas que se apresentam. Isso aumenta o leque. Hoje eu trabalho do Tatuquara ao Cachoeira, da Colônia Augusta ao Cajuru (...) Na eleição de 2004, eu fiz votos em todas as urnas. Eu participo de vários grupos de discussão. Ontem, participei de um jantar com empresários do Boqueirão, que é lazer, mas que se fala de política também. Era um compromisso meu de campanha: a
\end{abstract}

\footnotetext{
14 É o caso, por exemplo, do atual deputado estadual Alexandre Curi, neto de Aníbal Khury, ex-presidente da Assembléia Legislativa, a quem ele assessorou por algum tempo. Ângelo Vanhoni também, pois é filho de Vidal Vanhoni, ex-deputado estadual e ex-secretário de Educação do estado de 1956 a 1958. Outro caso é Ehden Abib, filho do ex-vereador Miguel Pedro Abib, que fundou a instituição hospitalar Francisco de Assis, em Rio Azul, e atuou na assistência social criando abrigos para deficientes físicos e idosos. Fábio Camargo é filho e neto de desembargadores do Tribunal de Justiça do Paraná, membro da tradicional família política Camargo, atuante na região há mais de dois séculos, parente do deputado federal Affonso Alves Camargo Neto, ex-senador, ex-ministro e neto do Presidente do Paraná, por duas vezes na República Velha, Affonso Alves Camargo (OLIVEIRA, 2007). Gustavo Fruet é filho de Maurício Fruet, ex-deputado e ex-prefeito de Curitiba. Ney Leprevost, neto e homônimo do político Ney Leprevost, exprefeito de Curitiba. Reinhold Stephanes Jr, filho do deputado federal e ex-ministro da Agricultura, Pecuária e Abastecimento, Reinhold Stephanes - que também já foi ex-ministro da Previdência e ex-secretário de planejamento do governo estadual.
} 
revitalização da Avenida Marechal Floriano Peixoto. Muitos nem estiveram comigo na campanha, mas fazem parte do grupo. Acho que você não quer fazer política só pelo voto, tem a satisfação pessoal também, que aquilo que a comunidade quer, ocorra” (João Claudio Derosso).

Os relatos aqui reproduzidos estão dispostos no trabalho acadêmico empreendido na especialização, com entrevistas realizadas em 2007, ${ }^{15}$ outros são de 2010, quando o modelo de pesquisa foi aperfeiçoado para a dissertação. ${ }^{16} \mathrm{O}$ político é filho de João Derosso, eleito vereador de Curitiba pela primeira vez em 1963, na segunda vaga conquistada pelo PL naquele pleito.

DIAGRAMA 02

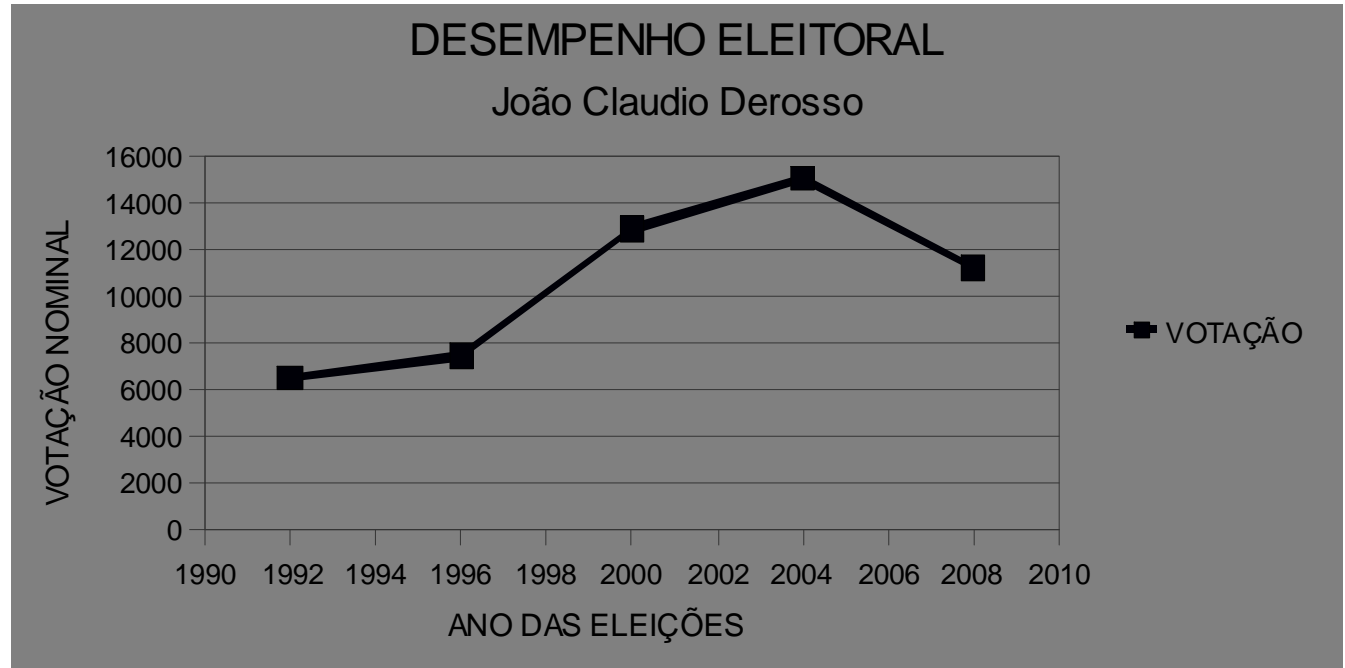

Durante os 25 anos seguintes, João Derosso se tornaria uma referência em eleições proporcionais na capital, auxiliando a consolidar bases eleitorais para políticos até então pouco conhecidos na cidade, como o radialista José Domingos, na década de 1970, e Reinhold Stephanes, nos anos 1980. Derosso foi o porta-voz da instalação da rede de eletricidade nos bairros do Xaxim e Umbará, chegando a ser chamado de "homem da luz" pelos vizinhos.

Nos anos de chumbo, João Derosso comporia a bancada da ARENA, sempre como um dos mais votados na capital. Ao abandonar a carreira eleitoral, passou o bastão da família ao filho João Claudio Derosso, eleito pela primeira vez em 1988.

Renata Bueno (PPS) obteve sucesso em sua primeira tentativa de ingressar na Câmara Municipal de Curitiba. Filiada ao PPS, partido dirigido pelo seu pai, Rubens Bueno, ela obtém

\footnotetext{
${ }^{15}$ Para essa pesquisa, foram entrevistados os seguintes vereadores, eleitos em 2004: André Passos (PT), Ângelo Batista (PP), Celso Torquato (PSDB), Elias Vidal (PP), João Cláudio Derosso (PSDB), Osmar Bertoldi (PFL), Serginho do Posto (PSDB) e Tico Kuzma (PPS).

${ }^{16} \mathrm{Na}$ dissertação, foram ouvidos Felipe Braga Côrtes (PSDB), Omar Sabbag Filho (PSDB), Julião Sobota/Julião da Caveira (PSC), Caíque Ferrante (PRP), Pedro Paulo (PT) e Zé Maria (PPS), eleitos em 2008.
} 
4.984 votos. Com 29 anos de idade, ela é advogada com especialização em direitos humanos e mestrado em direito público internacional, cursado na Itália. A experiência fez com que se tornasse representante brasileira do Partido Democrático Italiano. Em 2009, Renata era coordenadora geral da Fundação Astrojildo Pereira, instituto de apoio ao PPS, membro da Comissão de Gestão Pública da OAB/PR, conselheira da diretoria do Conselho da Mulher Executiva (CME) da Associação Comercial do Paraná (ACP), membro do conselho do Instituto dos Advogados do Paraná (IAP) e vice-presidente do Partido Popular Socialista (PPS).

O pai de Renata foi deputado estadual por quatro vezes nos anos 1980 e prefeito de Campo Mourão, no Norte do Paraná, em 1992. Rubens Bueno também foi secretário estadual do Trabalho e diretor-presidente da Fundação de Assistência Social (FAS) de Curitiba, no início da década de 1990, durante a gestão do prefeito Jaime Lerner. Obteve mais quatro mandatos de deputado federal e candidatou-se duas vezes ao governo do Paraná e uma à prefeitura de Curitiba, sem sucesso. Bueno era o presidente da legenda no Paraná e secretário nacional do partido quando sua filha foi eleita vereadora. Inicialmente filiados ao PPS em 2004, os vereadores Serginho do Posto e Tico Kuzma deixaram a legenda no pleito de 2008, atribuindo a decisão à falta de autonomia dentro do partido.

Juliano Borghetti é eleito vereador pelo PP em 2008 com 4.801 votos. Ele é irmão de Cida Borghetti (à época deputada estadual, eleita deputada federal em 2010), que por sua vez é casada com Ricardo Barros, político de tradicional família do Norte do Paraná. Juliano foi diretor da autarquia estadual Paraná Esporte, coordenando projetos sociais, antes da eleição proporcional de 2000, quando obteve 1.384 votos para a Câmara Municipal de Curitiba.

Nos anos seguintes, durante a gestão de Cássio Taniguchi, foi secretário de Esporte e Lazer do município - mesmo período em que entra em vigor a Lei Municipal de Incentivo ao Esporte. No primeiro mandato do prefeito Beto Richa, foi administrador da Regional do Pinheirinho.

A história desse grupo político começa com o pai de Ricardo, Silvio Barros, nos anos 1960. Ele foi seguidamente vereador, deputado estadual e deputado federal por Maringá e região. Na década seguinte foi prefeito, consolidando a sua influência regional. Ricardo Barros é eleito prefeito em 1988 e deputado federal quatro vezes consecutivas a partir de 1994. Silvio Barros II, irmão de Ricardo, é o prefeito reeleito de Maringá, com mandato até 2012.

Na década de 1990, Cida Borghetti será a diretora regional da Provopar e ocupará por duas a chefia do escritório de representação do Paraná em Brasília. Em 2000, ela perde a eleição para a prefeitura de Maringá, elegendo-se deputada estadual em 2002 e 2006. Juliano é a conexão do grupo político com o eleitorado de Curitiba, cidade que concentra 25\% dos eleitores do Paraná. 
DIAGRAMA 03

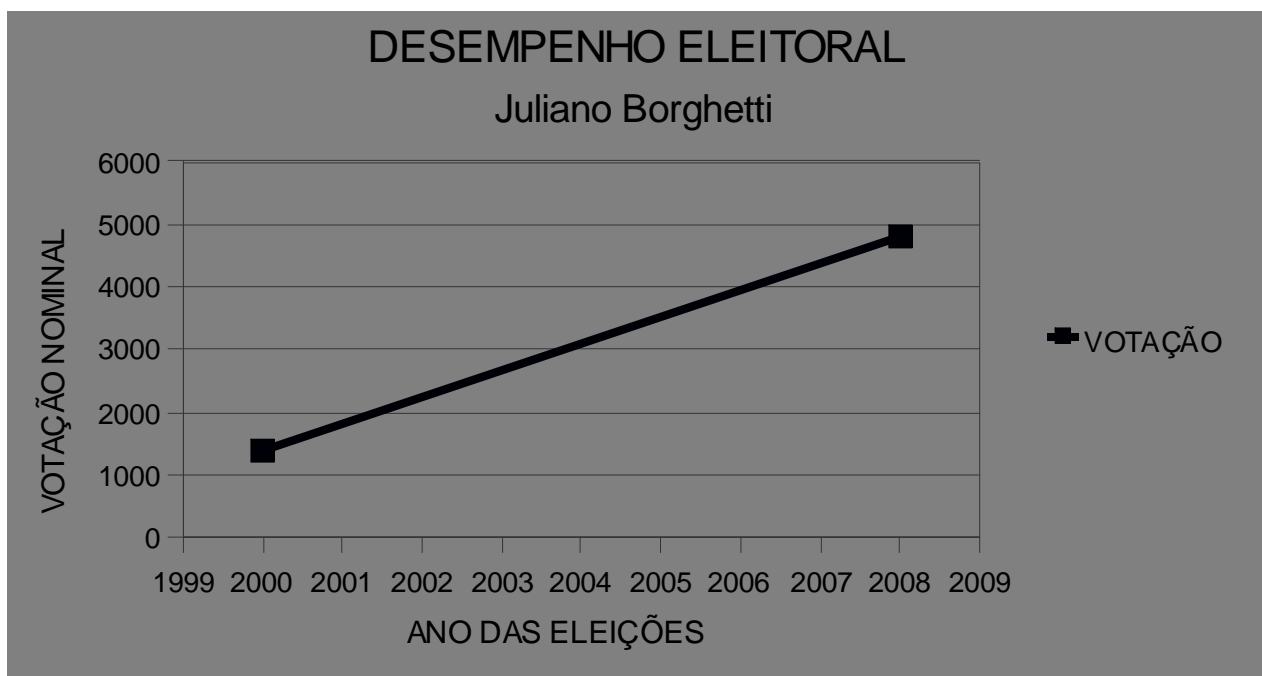

Jonny Stica também é eleito vereador já na sua primeira tentativa. Em 2008, ele obteve 4.016 votos pelo Partido dos Trabalhadores. O político é filho de Natálio Stica, vereador de Curitiba por três mandatos (1992, 1996 e 2000) e deputado estadual eleito em 2002. Durante o segundo mandato de Roberto Requião no governo do Paraná, Natálio assumiu a diretoria-comercial da Sanepar.

\begin{abstract}
Venho do Movimento Estudantil, fui presidente do Centro Acadêmico de Arquitetura e depois Presidente do DCE da PUC-PR. Logo, tive a sorte de ter muitos amigos ao meu redor, que me incentivaram a ser candidato e ajudaram a me eleger. Desde minha infância tive a oportunidade de acompanhar a trajetória política de meu pai Natálio Stica. Ele foi um dos fundadores do PT aqui no Paraná e esteve presente em causas muito importantes do nosso Estado. Por isso, tomei gosto pela coisa pública e desde muito cedo tive certeza que de alguma forma a política estaria presente em minha vida. A minha família é a base de tudo, é lá que tudo começa, e a presença deles em todos os momentos foi imprescindível. Contamos também com apoio de alguns militantes do PT que conhecemos durante a campanha e que deram uma contribuição significativa. (Jonny Stica)
\end{abstract}

A trajetória eleitoral de Jonny começa em 2004, quando foi presidente do Centro Acadêmico de Arquitetura e Urbanismo da PUC/PR, depois vencendo as eleições para presidente do Diretório Central dos Estudantes (DCE) da instituição, que contava com 24 mil alunos. Passou pelo Instituto de Pesquisa e Planejamento Urbano de Curitiba (Ippuc), na área técnica.

Omar Sabbag Filho (PSDB) foi o $27^{\circ}$ candidato mais bem votado entre os vereadores eleitos, com 5.498 votos. É filho do ex-prefeito Omar Sabbag e de Branca Casagrande, fundadores da primeira APAE do Paraná e sócios-fundadores do Clube Sírio-Libanês de Curitiba. A gestão Omar Sabbag deixou como legado para a cidade de Curitiba a construção do primeiro viaduto do município, próximo ao estádio da Vila Capanema; a inclusão do flúor na água distribuída para a 
população, como forma de combater as cáries; e a criação da FAS, pela esposa de Omar, por exemplo. Os fatos foram utilizados durante a campanha do candidato a vereador, compondo a comunicação social, mas sem centralidade.

"Nós não queríamos uma campanha do filho do Omar Sabbag, mas a campanha do Omar Sabbag Filho. Então, a gente procurou mais mostrar quem eu sou, de onde vim, meu pai, a minha mãe, o que já vivi, quais as contribuições que já dei à cidade. Foi uma decisão que a gente tomou. Por exemplo, uma das dúvidas: vamos usar só Omar Sabbag que é mais simples, né? Eu disse não, Omar Sabbag não sou eu, vamos usar Omar Sabbag Filho - e assim ficou" (Omar Sabbag Filho).

Professor universitário e dirigente partidário responsável pelo plano de governo do prefeito Beto Richa, Sabbag Filho obtém sucesso já na sua primeira eleição. O voto do político concentrouse nos bairros de melhor situação social da cidade, com grande penetração na comunidade árabe de Curitiba. Ocupou cargos na administração municipal na década de 1980 e na gestão recente do PSDB.

\begin{abstract}
"Eu percebi na minha campanha que, especialmente as pessoas de uma faixa etária um pouquinho mais avançada, tinham na memória quem tinha sido meu pai. Há que se levar em consideração que ele foi prefeito há quase 50 anos e, mesmo assim, ainda tem um forte registro dele na memória das pessoas, como alguém de gestão técnica, estruturando a cidade de Curitiba com uma visão de futuro (...) Eu vivi uma Curitiba dos anos 1980, do Mauricio Fruet, e passei a viver uma Curitiba dos anos 2000 com o Beto Richa. E antes disso eu havia vivido na Curitiba dos anos 1960, na época da adolescência, com o meu pai prefeito. Eu acho que isso também tem a ver com esse despertar para a política. Tem uma história de um ambiente familiar e de trabalho que acaba fazendo com que a gente siga uma vereda" (Omar Sabbag Filho).
\end{abstract}

Do partido, Sabbag Filho acredita ter recebido apoio de duas formas distintas, porém pouco associadas ao desempenho eleitoral. Ele destacou a importância do Instituto Teotoôio Vilela na elaboração das propostas que embasaram a sua candidatura a vereador. Também falou das agendas compartilhadas com o candidato da majoritária, situação que contribuiria para a votação final, mas não decisivamente. 
DIAGRAMA 03

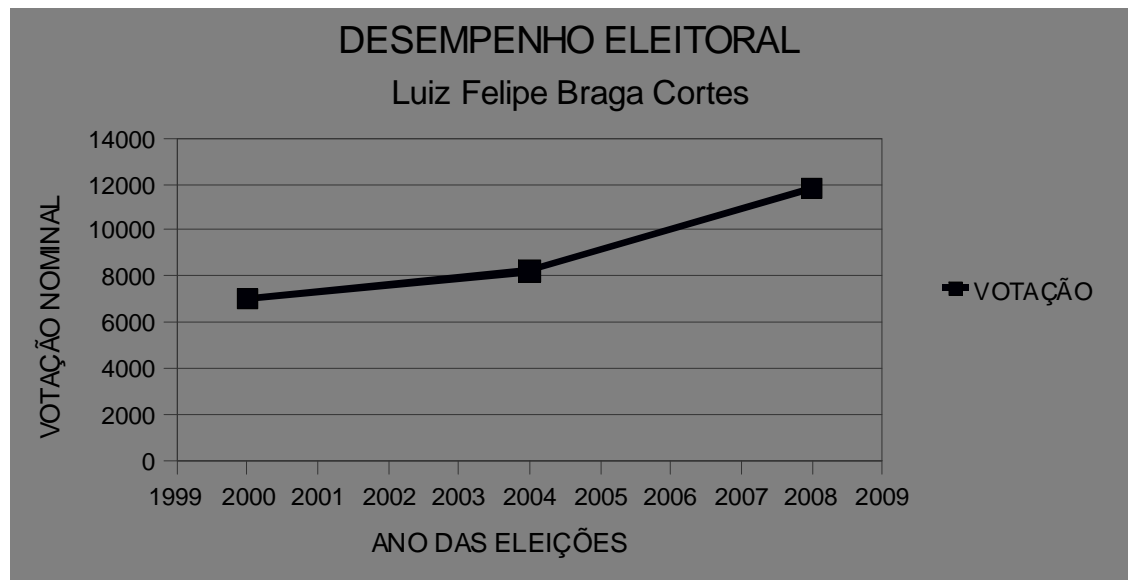

O candidato Felipe Braga Côrtes recebeu 11.817 votos em 2008, tendo esta sido a sua terceira eleição consecutiva para a Câmara Municipal. Ele acumula o capital político decorrente do pertencimento à família tradicional (o pai, Fabiano Braga Côrtes, foi deputado estadual, o tio Ney Braga governador do Estado e o irmão, Fabiano Braga Côrtes, vereador da capital antes dele). Acumula passagem pela diretoria de regularização fundiária da Cohab e um bom relacionamento com o setor da construção civil. É conselheiro do Coritiba Futebol Clube e da mesma geração que Gustavo Fruet e Beto Richa, com quem possui uma boa relação pessoal e política.

A primeira campanha é sempre a primeira, né?! Eu tinha família, meu irmão [Fabiano Braga Côrtes Jr] tinha sido vereador na década de 1990. Já tinha, mais ou menos, uma base que vinha dele, que foi vereador duas vezes. Ele tinha um conhecimento de gente que eu consegui aproveitar. Foi um passo importante e eu tinha essa motivação. Tinha essa coisa de ter a política em casa, eu gostava muito, pude aprender a fazer... A eleição foi uma dificuldade enorme, até quanto a "quem é filho de quem", "irmão de quem", por ser uma nova geração. Tinha o nome do meu pai, então me chamavam muito de Fabiano ainda (...) Não foi uma vitória completa, já que acabei não entrando de primeira, mas foi uma expressiva votação para a época. Foi uma votação muito grande, se eu não me engano, contabilizando no geral, fiquei em 19"' (Felipe Braga Côrtes).

Nesta eleição de estreia, em 2000, Felipe registra 7.006 votos. A marca indica o sucesso da campanha - então PFL, partido de situação - que soube animar a base eleitoral da família e associar-se ao bom desempenho da legenda. Vencida esta etapa, o político assume a primeira suplência do partido e é alocado em uma diretoria da Companhia de Habitação Popular de Curitiba (Cohab-CT). A experiência será utilizada por Felipe para ampliar as suas bases eleitorais.

"O trabalho do vereador, no dia a dia, é ter uma boa equipe, que possa fazer o atendimento à população. Ter um bom trabalho institucional com a prefeitura, para buscar o recurso que cabe àquela população. O recurso é pouco para tanta obra que precisa ser feita, daí você tenta trazê-lo para aquele lado que você tem mais referência. É o que a gente faz hoje com as emendas, que tem um resultado muito positivo. Você consegue direcionar o recurso para aquele que tem mais necessidade. Isso é legal, porque eu trabalho muito com associação de 
moradores.. (...) É uma relação de confiança que existe entre você e a comunidade, se você tiver um bom trabalho. Eu acredito na pessoa que entende assim: tenho um representante, o cara é político, logo cabe a ele atender a gente. Eu votei nele e preciso cobrar dele. E você tem que dar o retorno, mesmo que seja o "não". Você dando o retorno positivo, aquele eleitor começa a confiar em você, na classe política" (Felipe Braga Côrtes).

\section{DEMAIS VEREADORES}

A ideia de capital social de ligação está atrelada a redes de pessoas dispostas em formações horizontais. Ocorre entre indivíduos que compartilham características sociodemográficas, tais como família, vizinhos, amigos e colegas de trabalho. É o principal traço dos "vereadores do bairro", que investem tempo e recursos nas atividades destas pequenas comunidades e grupos.

No ano de 2008, consideramos este o traço preponderante nas candidaturas de Serginho do Posto, Tito Zeglin, Francisco Garcez, Aldemir Manfron, Dona Lourdes, Celso Torquato, Paulo Frote, Jair Cezar, João do Suco, Zezinho do Sabará, Aladim Luciano (PV) e Odilon Volkmann.

Existem também redes sociais constituídas ao redor do capital social de ponte: são formações entre comunidades distintas, que não compartilham estreitamente as características demográficas supracitadas, tais como associações civis ou de negócios. Ele é originado na defesa de interesses comuns a um grupo de pessoas, por isso a categoria é mais utilizada para tratar da ação de classes profissionais e de associações civis cujas bandeiras extrapolem os limites da própria organização.

Na eleição estudada, foi o caso de Denílson Pires, membro da diretoria do Sindicato dos Motoristas e Cobradores de Ônibus de Curitiba e Região Metropolitana (Sindimoc). Também de Jairo Marcelino, que antes da carreira parlamentar foi motorista de ônibus. Uma vez na Câmara de Vereadores - onde ingressou pela primeira vez em 1983, reelegendo-se sucessivamente desde então - passou a representar classes profissionais ligadas ao transporte, como taxistas e empresas privadas ligadas ao setor, nos seus mais diversos ramos. Julieta Reis, por sua vez, representa trabalhadores do comércio ambulante e do artesanato, sendo a responsável pela regulamentação das feiras e exposições realizadas na cidade. Já Professora Josete, servidora da rede pública de ensino desde 1985, participou da criação do Sindicato dos Servidores do Magistério Municipal de Curitiba (Sismmac), foi presidente da instituição e dirigente estadual da Central Única dos Trabalhadores (CUT).

Outros vereadores fazem das suas relações interpessoais momentos para a barganha de recursos adicionais para determinada pessoa ou comunidade. Estes políticos que se posicionam diante do eleitor como intermediadores dos cidadãos com as autoridades do poder público buscam 
acumular capital social de conexão - formação de redes verticais. É uma postura frequente em todos os aspirantes a uma carreira eleitoral, que geralmente só se configura como predominante quando a base eleitoral do político é muito distribuída.

Em 2008, Tico Kuzma, Beto Moraes, Sabino Picolo e Caíque Ferrante foram as opções, na dissertação, para exemplificar esse tipo de conversão de capital social em capital político. Em comum, eles possuíam base eleitoral menos delimitada geograficamente e experiência prévia na atividade política que os habilitava a pleitear com sucesso demandas no Executivo - apenas Ferrante, desse grupo, não era vereador na legislatura anterior.

Como já foi antecipado, outras duas tipificações, à guisa de complementação, estão presentes na obra de Portes (BROWN, 1999, p. 04) - que trabalha a noção de capital social num nível intermediário entre Bourdieu e Coleman. A primeira delas é a ideia de "solidariedade comprometida", importante para a compreensão de casos em que o desempenho eleitoral está firmemente atrelado à participação do político em alguma campanha de motivação cívica.

Trata-se da identidade instrumental entre pessoas que experimentam uma mesma situação, ou se sensibilizam com o grupo beneficiado. É a variável que melhor se acopla, em 2008, à trajetória política de Zé Maria e Pedro Paulo. O primeiro, voluntário na Escola de Educação Especial Primavera durante 25 anos, especializou-se em questões ligadas à defesa das pessoas com deficiência. Já Pedro Paulo sai da militância nas comunidades eclesiais de base da igreja católica, participando das pastorais da Juventude e Operária, e se torna coordenador do Fórum Estadual dos Direitos da Criança e do Adolescente. Nesta trajetória, passa a representar politicamente os conselheiros tutelares de Curitiba.

Para uma tentativa de compreensão sociológica da participação religiosa na política, e do papel desempenhado por "clubes de atividades", como o escotismo e os Rotarys, é importante atualizar a teoria do capital social com as observações de Portes (2000). O sociólogo anexará ao apanhado científico existente as motivações culturais e as regras de conduta. Para ele, existem certos "valores introjetados" que levam as pessoas a se relacionarem compulsoriamente, como se movidos por imperativos morais. ${ }^{17}$

No pleito analisado, este aspecto esteve ligado às campanhas de Valdemir Soares, membro da Igreja Universal do Reino de Deus, da Cantora Mara Lima e de Noemia Rocha, ambas da Igreja

\footnotetext{
17 “Como exemplo do tipo altruísta, determinados indivíduos podem pagar as suas dívidas no prazo estipulado, dar esmola com fins caritativos e obedecer ao código de estrada por se sentirem na obrigação de se comportarem de tal forma. As normas internalizadas que tornam possíveis estes comportamentos são então apropriáveis, como recursos, por terceiros. Neste caso, aqueles que detêm capital social são os restantes membros da comunidade, que podem alargar prazos de amortizações sem receio de fuga ao pagamento ou permitir que os seus filhos brinquem na rua sem preocupações" (PORTES, 2000, p.138).
} 
Assembleia de Deus. Os três políticos desempenham diversas atividades em grupos específicos dentro das suas congregações. Dirceu Moreira, político com atuação no bairro CIC, também pode ser alocado aqui pelo forte vínculo que possui com a Igreja Adventista do Sétimo Dia.

Miguel (2003b) já apontava o papel dos meios de comunicação como catalisadores da conversão de outros capitais em capital político, pois garantem uma maior difusão da informação eleitoral entre os ouvintes/eleitores. Quando o assunto é rádio, então, a situação ganha contornos mais nítidos, como demonstrou Márcia Vidal Nunes, ao publicar no ano de 2000 a sua tese de doutoramento sobre esse processo acontecendo também na região Nordeste. Intitulada "Rádio e política: do microfone ao palanque, os radialistas políticos em fortaleza (1982-1996)", a tese procura esmiuçar os mecanismos que elevam os casos de sucesso provenientes das candidaturas de radialistas. $^{18}$

Não foi encontrada referência teórica a essa situação na literatura específica do capital social, mas as suas características parecem acoplar-se ao campo de pesquisa no sentido em que o trabalho como comunicador social resulta na obtenção de capital político. Até pesquisa que requalifique essa conversão de capitais, optou-se por tipificar essa atividade como instrumentalização de uma rede social para obtenção dos recursos alocados nos laços fracos que se formam entre a figura pública e sua comunidade de ouvintes.

Em 2008, sobressaem-se nesse ramo em Curitiba: José Roberto Aciolli dos Santos, Roberto Hinça, Mario Celso Cunha, Emerson Prado e Algaci Túlio - que retornou a um cargo eletivo após participações na cena política nos anos 1980 e em 1998, quando foi vice-prefeito. Durante todo o período teve programas de rádio e televisão.

Nesta mesma classificação está o Professor Galdino, cuja eleição é decorrente de um processo de construção do eleitorado, reforçada a cada dois anos com uma campanha baseada na comunicação direta. Equipado com uma bicicleta e uma caixa de som, ele percorre lugares de intenso tráfego, repetindo jingles e posicionando-se como "um político diferente". O caráter folclórico da atividade o transformou em uma celebridade local.

Em nenhum momento, na exposição desses dados, houve a defesa das relações sociais como os únicos componentes do desempenho eleitoral. Pelo contrário, uma literatura mais crítica já demonstrou como o abuso do poder econômico, por exemplo, interfere na composição do capital político e na apuração final dos votos. A análise dos dados coletados, contudo, aponta que

\footnotetext{
18 “O político se apropria do mediático, para construir uma nova forma de fazer política. É a política mediatizada. No caso dos radialistas, há um processo de instrumentalização do medium rádio que pode ou não ser deliberada. No início, pode até ser algo não planejado, mas à medida que o radialista se firma, projeta sua imagem, e adquire respeito e credibilidade junto à população, ele pode transformar esse "capital" pessoal no seu passaporte de ingresso à carreira política" (NUNES, 2000, p. 354).
} 
existe preocupação objetiva por parte dos políticos com esse aspecto da sua vida pública. Em relatos pessoais, eles afirmaram estimular esta reciprocidade, dispondo de tempo e recursos para se relacionarem com quem acreditam ser o seu próprio eleitorado.

\section{REFERÊNCIAS BIBLIOGRÁFICAS}

ABRANCHES, S. Presidencialismo de coalizão: dilema institucional brasileiro. In: TAVARES, J. A. G. (Org.). O sistema partidário na consolidação da democracia brasileira. Brasília: Fundação Teotônio Vilela, 2003. Cap. 1. p. 22-98.

ABRUCIO, F. L. Os barões da Federação - os governadores e a redemocratização brasileira. São Paulo: Hucitec, 1998. 253 págs.

. A reconstrução das funções governamentais no federalismo brasileiro. In: CARNEIRO, J. M. B.; HOFMEISTER, W. Federalismo na Alemanha e no Brasil. São Paulo: Konrad Adenauer, 2011. 223 págs.

AQUINO, J. A. As teorias de ação social de Coleman e de Bourdieu. Humanidades e Ciências Sociais, Fortaleza, v. 2, n. 2, 2000, p. 17-29.

BEZERRA, M. O. Em nome das bases - política, favor e dependência pessoal. Rio de Janeiro: Relume Dumará: Núcleo de Antropologia da Política, 1999. 275 págs.

BONFIM, W. L. de S.; SILVA, I. N. da. Instituições políticas, cidadania e participação: a mudança social ainda é possível? Revista de Sociologia e Política, Curitiba, n. 21, p.109-123, nov. 2003.

BOURDIEU, P. Questões de sociologia. Rio de Janeiro: Marco Zero, 1983.

. A estrutura invisível e seus efeitos. In . Sobre a televisão. Rio de Janeiro: Jorge Zahar, 1996. p. 55-97.

. O poder simbólico. 3.ed. Rio de Janeiro: Bertrand Brasil, 2000. 311 págs.

. A distinção. Crítica social do julgamento. $1^{\mathrm{a}}$ ed. São Paulo: Edusp; Porto legre: Zouk, 2007. 560 págs.

2007. p. 65-69.

O capital social - notas provisórias. In Escritos de Educação. Petrópolis: Vozes,

. Os três estados do capital cultural. In Escritos de Educação.

Petrópolis: Vozes, 2007. p. 71-80.

Reprodução cultural e reprodução social. In A economia das trocas simbólicas.

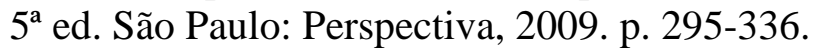

BROWN, T. F. Theoretical Perspectives on Social Capital. 1999. 14 págs. Disponível em 
http://jhunix.hef.jhu.edu/ tombrown/Econsoc/soccap.html

BURT, R. Second-hand Brokerage, evidence on the importance of local structure for managers, bankers and analysts. Chicago: University of Chicago Graduate School of Business, 2006. 68 págs.

CAMARGO, A. Federalismo cooperativo e o princípio da subsidiariedade: notas sobre a experiência recente do Brasil e da Alemanha. In: CARNEIRO, J. M. B.; HOFMEISTER, W. Federalismo na Alemanha e no Brasil. São Paulo: Konrad Adenauer, 2011. 223 págs.

CASTRO, I. Problemática qualitativa e quantitativa do 'capital social': uma exploração. Iseg/Socius, Lisboa, n. 03, jan. 2006. 33 págs.

COLEMAN, J. S. Social Capital. In , Foundations of Social Theory. Cambridge: Harvard

University Press, 1994. p. 300-324.

DEGENNE, A. Social capital: a theory of social structure and action. Tempo Social, São Paulo, v. 16, n. 2, p. 303-305, nov. 2004.

FERREIRA, L. N. O financiamento de partidos políticos e de campanhas eleitorais no contexto da reforma política brasileira. Estudos Eleitorais, Brasília, v. 6, n. 1, p. 91-110, jan./abr. 2011.

FLEURY, S. J. F. Redes de proteção: incentivos, escolhas e comportamentos na política brasileira. Belo Horizonte, 2009. 219 f. Tese - Departamento de Ciência Política da Faculdade de Filosofia e Ciências Humanas da Universidade Federal de Minas Gerais.

FUKUYAMA, F. Capital Social. In: HARRISON, L. E.; HUNTINGTON, S. P. (Org.) A cultura importa, Rio de Janeiro: Record, 2002. p. 155-173.

GOLDENBERG, M. A arte de pesquisar: como fazer pesquisa qualitativa em ciências sociais. $5^{\mathrm{a}}$ ed. Rio de Janeiro: Record, 2001. p. 33-43.

GROOTAERT, C.; NARAYAN, D.; JONES, V. N.; WOOLCOCK, M. Questionário Integrado para Medir Capital Social. Banco Mundial. jun. 2003. 73 págs.

KEINERT, F. C.; SILVA, D. P. A gênese da ciência política brasileira. Tempo Social, São Paulo, v. 22, n. 1, jun. 2010, p. 79-98.

KUSCHNIR, K.; CARNEIRO, L. P. 1999. As dimensões subjetivas da política: cultura política e antropologia da política. Estudos Históricos, Rio de Janeiro, v. 13, n. 24, p. 227-250.

LEAL, V. N. Coronelismo, enxada e voto. $O$ município e o regime representativo no Brasil. $3^{\mathrm{a}}$ ed. Rio de Janeiro: Editora Nova fronteira, 1997. 440 págs.

LALLEMENT, M. O ponto de vista culturalista. IN História da ideias sociológicas - de

Parsons aos contemporâneos. Petrópolis: Vozes, 2004. p. 75-109.

LESSA, R. Da interpretação à ciência: por uma história filosófica do conhecimento político no Brasil. Lua Nova, São Paulo, n. 82, 2011, p. 17-60. 
LIN, N. Building a network theory of social capital. Connections, Florida, n. 22, p. 28-51, 1999.

. Theory and research. In Social Capital: a theory of social structure and action.

Cambridge University Press: Cambridge, 2001. p. 1-11.

LUNDASEN, S. Podemos confiar nas medidas de confiança? Opinião Pública, Campinas, v. 8, n. 2, p. 304-327, out. 2002.

MAINWARING, S. Democracia presidencialista multipartidária: o caso doBrasil. Lua Nova, São Paulo, n. 28/29, p. 21-74, mai./jun. 1993.

MARTELETO, R. M.; SILVA, A. B. de O. e. Redes e capital social: o enfoque da informação para o desenvolvimento local. Ciência da Informação, Brasília, v. 33, n. 3, p. 41-49, set./dez. 2004.

MIGUEL, L. F. Representação política em 3-D. Elementos para uma teoria ampliada da representação política. Revista Brasileira de Ciências Sociais, São Paulo, v. 18, n. 51, p. 123-140, fev. 2003a.

Capital político e carreira eleitoral: algumas variáveis na eleição para o Congresso brasileiro. Revista de Sociologia e Política, Curitiba, n. 20, p. 115-134, jun. 2003b.

MARQUES, E. Os mecanismos relacionais. Revista Brasileira de Ciências Sociais, São Paulo, v. 22, n. 64, p.157-161, [online] 2007.

OLIVEIRA, R. C. de. O silêncio dos vencedores. Genealogia, classe dominante e Estado no Paraná. Curitiba: Moinho do Verbo, 2001. 447 págs.

(Org.) A construção do Paraná moderno. Políticos e política no governo do Paraná de 1930 a 1980. Curitiba: SETI, 2004. 420 págs.

Famílias, poder e riqueza: redes políticas no Paraná em 2007. Sociologias, n.18, Porto Alegre, jul/dez. 2007.

Na Teia do Nepotismo. Sociologia Política das Relações de Parentesco e Poder Político no Brasil. 1. ed. Curitiba: Insight, 2012. 272 págs.

PORTES, A. Capital social: origens e aplicações na sociologia contemporânea. Sociologia: problemas e práticas, n. 33, 2000, p. 133-158.

POUPART, J. A entrevista de tipo qualitativo: considerações epistemológicas, teóricas e metodológicas. In: VVAA. A pesquisa qualitativa: enfoques epistemológicos e metodológicos. Petropólis: Vozes, 2008. p. 215-253.

PUTNAM, R. D. Capital social e desempenho institucional In: Comunidade e democracia: a experiência da Itália moderna. 9. ed. Rio de Janeiro: Fundação Getúlio Vargas, 1994. p. 173193.

REHBEIN, M. P. Curitiba, 50 anos de eleições municipais. Curitiba, 2008. 403 págs. Dissertação 
(Sociologia). Setor de Ciências Humanas, Artes e Letras. Universidade Federal do Paraná.

REIS, B. P. W. Capital social e confiança: questões de teoria e método. Revista de Sociologia e Política, Curitiba, n. 21, p. 35-49, nov. 2003.

SANTOS, F. Patronagem e poder de agenda na política brasileira. Dados, Rio de Janeiro, v. 40, n. 3, 1997.

SANTOS, W. G. Sessenta e quatro: anatomia da crise. São Paulo: Vértice, 1986. 195 págs.

SILVEIRA, F. E. Pesquisas, enquetes e estudos eleitorais. Civitas, Porto Alegre, v. 2, n. 2, p. 351384, 2002.

\title{
RELATIONSHIP OF RELATIONS AND ELECTORAL PERFORMANCE PROPORTIONAL ELECTIONS IN 2008 IN CURITIBA
}

\begin{abstract}
This article takes up the main aspects of my dissertation Master's in Sociology, when I have participated of UFPR's NEP. Text emphasizes a research modeling on kinship relations and electoral performance. At the time, it sought to examine the components of the web of relationships embedded in the conquest of the vote, taking as a starting point Miguel's research (2003b) on the structuring of the political career in Brazil - in which analysis the notion of social capital appears as possibility of understanding for the successful candidates "newbies". Starting with the electoral performance statistics and prosopographic research on the elected councilors in 2008 in the city of Curitiba - capital of Paraná State, at that time with approximately 1.7 million inhabitants - were selected 6 of 38 winners. They underwent a qualitative interviews whose purpose was to show they had differential access to resources embedded in social networks, civil associations and mutual trust schemes. Thus, the social capital is analyzed in the relational level, unveiling electoral strategies: mediation of resources and information, to belong to traditional families, be part of communities that share demographic characteristics or interests in common.
\end{abstract}

Keywords: Political behavior. Elections. Social Capital. Kinship 